НОР-АРЕВЯН Оксана Аведиковна - кандидат социологических наук, доцент; доцент Института социологии и регионоведения Южного федерального университета (344006, Россия, г. Ростов-наДону, ул. Большая Садовая, 105; noroks@yandex.ru)

\title{
ИНСТИТУЦИОНАЛЬНЫЕ УСЛОВИЯ ПОДДЕРЖКИ МЕДИЦИНСКИХ ДИНАСТИЙ В СОВРЕМЕННОМ РОССИЙСКОМ ОБЩЕСТВЕ
}

\begin{abstract}
Аннотация. Статья посвящена анализу институциональных условий поддержки профессиональных династий врачей в современном российском обществе. Автор рассматривает условия, способствующие и препятствующие профессиональному воспроизводству в семье, трудовом коллективе. Посредством анализа преимуществ и недостатков внутрисемейного межпоколенного профессионального воспроизводства определяются возможные перспективы развития наследственности медицинской профессии. Автор предлагает выявленные институциональные барьеры решать на федеральном и региональном уровнях посредством разработки комплексной системы институциональной поддержки профессиональных династий врачей и популяризировать ее результаты в средствах массовой информации.
\end{abstract}

Ключевые слова: профессиональная преемственность, профессиональная династия, врач, институциональная поддержка, барьеры институциональной поддержки, институциональные инструменты

$\mathrm{C}$ егодня каждый второй россиянин считает врача героем нашего времени, и это объективно связано со сложившейся острой эпидемиологической ситуацией в нашей стране и в мире в целом. Медицина всегда держалась и держится не столько на передовых технологиях и препаратах (хотя это тоже очень важно), сколько на людях!

По результатам опроса Всероссийского центра изучения общественного мнения от 23 марта 2020 г. в связи с распространением нового вируса COVID-19 в мире и в России на плечи врачей и медицинских сотрудников легла огромная нагрузка, связанная с предотвращением распространения и лечением этого инфекционного заболевания. Потребовалась и перестройка всей системы здравоохранения, которая была вынуждена быстро адаптироваться и развиваться в ситуации угрозы национальной безопасности. Половина наших соотечественников (49\%) выделили представителей медицинской профессии из целого списка общественно значимых специальностей, буквально возведя врача в ранг героя нашего времени, а $61 \%$ демонстрируют высокий уровень доверия российским врачам. Профессия врача всегда воспринималась социально значимой и общественно полезной, что лежит в основе формирования положительного отношения к ней среди россиян. Врачи и ранее возглавляли рейтинг престижных профессий. Так, по результатам опроса ВЦИОМа, в октябре 2018 г. каждый четвертый россиянин (26\%) считал профессию врача престижной, при этом престиж профессии в сравнении с предыдущими годами измерения вырос в 2 раза (по $12 \%$ в 2012 г. и 2009 г., $11 \%$ в 2006 г.) ${ }^{1}$.

Профессия врача всегда была нужна, важна и востребована. Изменяется ее престиж, отношение к ней общества. Ранее, в 2018 г., ВЦИОМ представил дан-

${ }^{1}$ Врач - самая важная профессия. Доступ: https://wciom.ru/index.php?id=236\&uid=10208 (проверено 11.07.2020). 
ные опроса о том, какие профессии россияне считают наиболее подходящими для своих детей и внуков. И снова в рейтинге наиболее предпочтительных профессий для своих детей на первом месте находится профессия врача (4,17 баллов из 5 возможных). Причем среднее значение за последние 8 лет выросло с 3,9 баллов ${ }^{1}$.

Вопрос о династийности в профессии врача неоднозначен. С одной стороны, династийность - это хорошо. На вопрос: «Нужно ли поддерживать семейственные связи в медицине?» - министр здравоохранения РФ Вероника Скворцова в 2018 г. отвечает следующее: «На мой взгляд, династийность в медицине - это очень хорошо, а семейственность - плохо. Любая династия вызывает глубокое уважение» 2 .

Так надо ли поддерживать профессиональные династии, или они в этом не нуждаются, и их развитие идет по инерции? Какова роль профессиональных династий? Какие положительные и отрицательные стороны профессиональных династий? Нужна ли поддержка профессиональных династий? Теоретические размышления на этот счет можно найти в научных работах российских ученых [Вольчик, Посухова 2019; Калашникова 2012; Левочкина 2015; Максимова 2014; Мостовая, Посухова, Клименко 2019; Посухова 2013]; можно также обратиться и к эмпирическим данным.

Несмотря на то что по результатам опроса ВЦИОМа, проведенного в июне 2008 г. $^{3}$, лишь $3 \%$ следуют семейной традиции, династийности, более половины россиян полагают, что трудовые династии нужны (35\% - скорее да, 25\% - да), а $27 \%$ наших соотечественников, напротив, полагают, что нет необходимости в существовании профессиональных династий $(18 \% \text { - скорее нет, } 9 \%-\text { нет })^{4}$.

Положительной стороной профессиональных династий россияне чаще всего называют возможность передачи профессионального опыта (26\%). К плюсам также относят преданность профессии, более высокий уровень профессионализма и сохранение традиций профессии (по 5\%), 3\% указывают на быстрое освоение профессии, а $2 \%$ не видят никаких положительных сторон в существовании трудовых династий. В то же время большинство россиян $(57 \%)$ затрудняются в ответе на этот вопрос, но при этом подавляющее большинство респондентов (78\%) не могут назвать отрицательные стороны в существовании трудовых династий, но 6\% убеждены, что их нет. Только 5\% полагают, что минус заключается в отсутствии у детей права выбора профессии. Также наши сограждане указывают такие недостатки, как постоянная работа с родственниками, узость взглядов и то, что вакансии достаются не квалифицированным работникам, а членам семьи.

Почти $1 / 3$ россиян (30\%) считают, что поощрять представителей трудовых династий не следует. Среди тех, кто выражает противоположное мнение, наиболее распространена точка зрения, что «нужно проводить бесплатное обучение профессии детей представителей трудовой династии» (31\%). Еще $20 \%$ предлагают ввести денежные поощрения, $19 \%$ - оплачивать курсы повышения

1 Все профессии нужны, все профессии важны. Доступ: https://wciom.ru/index. php?id=236\&uid=9392 (проверено 11.07.2020).

2 Министр Вероника Скворцова дала интервью «Медицинской газете». Доступ: https:// www.rosminzdrav.ru/news/2018/02/15/7121-ministr-veronika-skvortsova-dala-intervyumeeditsinskoy-gazete (проверено 11.07.2020).

3 Инициативный всероссийский опрос ВЦИОМ проведен 14-15 июня 2008 г. Опрошены 1600 чел. в 140 населенных пунктах в 42 областях, краях и республиках России. Статистическая погрешность не превышает $3,4 \%$.

4 Профессия по наследству: хорошо или плохо? Доступ: https://wciom.ru/index. php?id=236\&uid=2501(проверено 11.07.2020). 
квалификации представителям трудовых династий. $14 \%$ россиян высказываются за обеспечение таких семей бесплатными путевками на отдых, 9\% - за привлечение последователей семейной традиции к управленческим должностям. $20 \%$ затруднились ответить.

Вместе с тем медицина - это та сфера, где наиболее распространены профессиональные династии и сохраняется профессиональная преемственность.

В научных исследованиях анализируются причины возникновения и поддержания династийности в профессиональной деятельности (равно как и причины прерывания династий), которые в полной мере могут быть отнесены и к институциональной поддержке преемственности медицинской профессии. Так, Е.М. Колесникова останавливает свое внимание на внутрисемейных межпоколенческих ресурсах, к которым относит: 1) родительское программирование; 2) наследование образовательной траектории; 3) наследование профессиональных навыков, копирование, а затем осознание особенностей профессиональной деятельности родителей; 4) профессия родителей может быть единственно возможным выбором ребенка; 5) династия рассматривается как возможность восходящей социальной мобильности [Колесникова 2016]. Коллектив авторов под руководством В.А. Мансурова дополняет перечень еще двумя пунктами: это гордость за принадлежность к конкретной династии и то, что династия обеспечивает быстрый профессиональный старт младшим членам династии, более комфортное вхождение в профессию, курирование продвижения по служебной лестнице и получение выгодных предложений на рынке труда [Инженерные династии... 2017: 22].

В развитии профессиональных династий врачей очень важна институциональная поддержка, где первоочередную роль играет институт семьи. Семейные профессиональные династии - это не только передача знаний, накопленного опыта, секретов мастерства от поколения к поколению, но и особая атмосфера, в которой дети принимают решение пойти по стопам своих родителей. Развитие профессиональной династии становится важной семейной задачей.

Каждый человек, делая свой профессиональный выбор, ориентируется на множественные факторы, такие как личностные интересы, рекомендации семьи и семейные традиции (династийнность в профессии), престижность профессии, востребованность профессии на рынке труда. Семья осуществляет функции передачи социального и профессионального опыта, предоставления защищенного социального пространства для члена семьи и поддержания определенного культурного образца, формирующегося в результате осознанного и неосознанного копирования профессиональных установок в семейном поведении.

Традиционно перспективы развития профессиональных династий врачей связываются с ответственностью семьи за продолжение семейного дела. И немаловажное значение имеют благоприятные условия согласования интересов профессиональной династии с институциональной средой, которую создают властные структуры как федерального, так и регионального уровня.

Однако на характер воспроизводства профессии врача в семье могут оказывать влияние некоторые институциональные барьеры. Не все дети готовы примерить на себя роль продолжателя династии; в этом случае они заявляют протест сложившейся стратегии профессионального воспроизводства. Порой молодые люди делают выбор «от противного». Психологи называют следующие причины такого поведения: 1) юношеское желание вырваться из-под родительской опеки, изменить привычную модель отношений с родителями, найти собственные пути самореализации; 2) негативный пример родителей, который не вдохновляет ребенка на то, чтобы заняться тем же видом деятель- 
ности; 3) наоборот, чрезмерный успех родителей, и ребенок опасается, что, выбирая тот же путь, он навсегда останется в их тени. Психологи считают, что сегодня трудовые династии могут появиться только в семьях, где «отцы» добились успеха и с интересом занимаются своим делом, оставляя за ребенком право выбора. Тогда вместе с профессиональными секретами по наследству передается любовь к работе ${ }^{1}$.

Постепенно ответственность за поддержку профессиональной династийности врачей переходит к государству и становится целью институциональной поддержки государства и общественных структур. И действительно, развитие системы здравоохранения является важнейшей идеологической задачей российского государства.

Развитие инфраструктуры здравоохранения и кадровое обеспечение медицинской отрасли являются важными элементами институциональной поддержки, направленными на профессиональное воспроизводство медицинской профессии. Вместе с тем предложенные правительством меры нельзя рассматривать в полной мере как государственные инструменты стимулирования профессионального воспроизводства медицинской профессии, но очевидно, что чем стабильнее, престижнее, успешнее будут чувствовать себя медицинские работники, тем скорее в эту отрасль потянется молодежь, в т.Ч. и вслед за своими старшими товарищами.

Институциональным барьером профессионального воспроизводства выступает существующее на сегодняшний день ограничение, не позволяющее работать в подчинении медикам, имеющим кровнородственные связи. Это касается прежде всего сферы управления здравоохранением ${ }^{2}$. Установленный в 2013 г. запрет не способствует сохранению преемственности поколений, поэтому в 2017 г. с целью сохранения традиций и исторической преемственности поколений в сферах науки, образования, здравоохранения, культуры и социальной защиты Минтруд России подготовил изменения в действующее законодательство, согласно которым данный запрет не распространяется на вышеуказанных работников, в случаях: 1) если финансово-хозяйственные полномочия работниками - близкими родственниками (свойственниками) осуществляются вне условия непосредственной подчиненности или подконтрольности одного из них другому; 2) если один из работников осуществляет непосредственно деятельность, связанную с выполнением работ, оказанием услуг, относящихся к основным видам деятельности организации, например в сфере науки, культуры, здравоохранения, социальной защиты, образования, спорта (ученый, искусствовед, балерина, актриса, практикующий врач, учитель, спортсмен, юрист и т.п.) ${ }^{3}$.

1 Профессия в наследство. Доступ: https://present-dv.ru/obraz/professiya-v-nasledstvo-684 (проверено 11.07.2020).

2 Постановление Правительства РФ от 08.07.2013 N 568 «О распространении на отдельные категории граждан ограничений, запретов и обязанностей, установленных Федеральным законом "О противодействии коррупции" и другими федеральными законами в целях противодействия коррупции». Доступ: http://www.consultant.ru/cons/cgi/online.cgi?rnd= 6AE083EB8D5FC874BAA46FD1FA894EBC\&req=doc\&base $=$ LAW\&n=212970\&REFFIELD $=134 \&$ REFDST $=100003 \&$ REFDOC $=277438 \&$ REFBASE $=$ LAW $\&$ stat $=$ refcode $\% 3$ D $10881 \% 3 \mathrm{~B}$ index\%3D6\#p93z9tqqi6 (проверено 31.03.2020).

3 Письмо Минтруда России от 16.05.2017 N 18-2/B-297 «О применении отдельных положений постановления Правительства РФ от 05.07.2013 N 568». Доступ: http://www. consultant.ru/cons/cgi/online.cgi? req $=$ doc\&cacheid=6E7DEB165CD88F18D8216AF53B84E8 $\mathrm{B} 2 \&$ mode $=$ backrefs \&div $=$ LAW \&opt $=1 \&$ SORTTYPE $=0 \&$ BASENODE $=1-1 \&$ ts $=153711585709$ 98720850\&base $=$ LAW \&n=277438\&rnd $=6$ AE083EB8D5FC874BAA46FD1FA894EBC\#c6pjzxf wz3k (проверено 31.03.2020). 
Основными государственными задачами в сфере осуществления государственной политики по отношению к потомственному наследованию профессии выступают меры по повышению символического статуса династии и пропаганда преимуществ династийности.

Система институциональной поддержки профессиональных династий в медицинской сфере нуждается в серьезной информационной поддержке, которая осуществляется посредством федеральных и региональных средств массовой информации. В каждом регионе России есть свои трудовые династии семейные коллективы, в которых бабушки и дедушки, отцы и матери, дети и внуки на протяжении многих лет верны одной профессии, в т.ч. и профессии врача. О таких славных династиях пишут биографические очерки, публикуют материалы интервью, реализуют музейные проекты.

Один из богатых примеров - Алтайский край. Собраны материалы о 82 трудовых династиях Алтайского края ${ }^{1}$. Уникальный опыт презентации собранных материалов о медицинских династиях в Ярославской обл. послужил толчком реализации музейного проекта «Самая богатая на династии профессия - врач» 2 .

Активно реализуются и телевизионные проекты. Так, во Владимирской обл. ТВ МИГ продолжает проект, в котором рассказывается о династиях врачей Владимирской обл. ${ }^{3}$ Телевизионные сюжеты о династиях врачей выходили в новостных программах федеральных и региональных каналов 4 .

В Кемеровской обл., например, биографические очерки опубликованы на официальном сайте ГБУЗ Кемеровской области «Междуреченская городская больница» (http://mcgb.ru/), в которой работают дети и внуки тех врачей, которые своими силами смогли организовать и «вырастить» отделения этой больницы 5 .

Трудовым, профессиональным династиям значительное место уделяется на страницах газет, специализированных журналов и буклетов, интернет-сайтов. В 2015 г. была издана книга «Российские династии». Среди наиболее распространенных династических профессий, упоминаемых в сборнике, 1-е место занимают профессии учителей-педагогов (1 742 упоминания), на 2-м месте медики (681 упоминание), на 3-м месте военные (148) [Иванова, Юрьев 2018].

Информационно-просветительская работа средств массовой информации направлена на популяризацию профессиональных династий врачей, и СМИ выполняют очень важную задачу - осуществляют поддержку профессиональной династийности. Исследование судеб и биографий потомственных врачей, представленное в открытом доступе в СМИ, позволило автору выделить особенности и сформулировать следующие преимущества профессиональной преемственности у представителей медицинской профессии: 1) предопределенность выбора: не требуется принимать решение о будущей профессии, ребенок в семье врача уже с раннего детства включен в процесс профессиональной

1 80-летию Алтайского края - 80 трудовых династий. Доступ: https://www.aksp.ru/work/ activity/dolgoletie/ak_80_let/dinastii/ (проверено 11.07.2020)

2 Самая богатая на династии профессия - врач / Музеи Ярославля. Доступ: https:// yarodom.livejournal.com/1857925.html (проверено 11.07.2020).

3 Династия врачей. Праздновы. Доступ: https://www.tv-mig.ru/news/nashi-proekty/ dinastiya-vrachey-prazdnovy/ (проверено 11.07.2020).

4 Афанасьев П. В Томске живет и работает уникальная семья - четыре поколения медицинских работников [видео-файл]. - Первый канал. Доступ: https:/www.1tv.ru/ news/2009-06-20/169230-v_tomske_zhivet_i_rabotaet_unikalnaya_semya_chetyre_pokoleniya_ meditsinskih_rabotnikov (проверено 07.04.2020); Династия врачей [видео-файл]. РоссияДагестан. Доступ: http://gtrkdagestan.ru/video/dinastiya_vrachey/ (проверено 10.03.2020).

5 Медицина сильна династиями. Доступ: http://mcgb.ru/doc/cgbbook/2.pdf (проверено 11.07.2020). 
социализации; 2) создание особой атмосферы первичной профессиональной социализации, передача профессиональных навыков, знаний, опыта и даже авторских методов лечения (в отдельных случаях); 3) профессия врача является ценностью, обладает социально-культурной значимостью и престижем для представителей семейной группы; 4) династийность снижает риски прихода в профессию случайных людей [Нор-Аревян 2019].

Важным информационным поводом для поддержки династий в СМИ выступают конкурсы, проводимые на федеральном и региональном уровне.

В 2016 г. в Общественной палате РФ состоялся интернет-форум «Династии земли российской», организованный общероссийской общественной организацией «Национальная родительская ассоциация социальной поддержки семьи и защиты семейных ценностей» при поддержке комиссии ОП РФ по развитию науки и образования. В форуме приняли участие представители профессиональных династий из регионов, которые рассказали о трудовых культурных традициях России, а также о принципах воспитания у подрастающего поколения уважительного отношения к труду и достижениям предков 1 .

В целях содействия возрождению, сохранению и развитию трудовых династий в профессиональной медицинской деятельности профсоюз работников здравоохранения РФ организовал и провел в 2018 г. конкурс «Трудовые медицинские династии» 2 .

В 2020 г. Национальная родительская ассоциация проводит VII Всероссийский конкурс школьных генеалогических исследований «Моя родословная» с участием семей соотечественников, проживающих за рубежом. Одна из номинаций конкурса «Наша династия» предполагает описание профессиональной династии, ее роли в жизни общества и семьи в целом. Посредством этого конкурса государство реализует важнейшую идеологическую задачу - воспитание подрастающего поколения. В задачи конкурса входит в т.ч. развитие мотивации обучающихся к формированию ответственного отношения к преемственности поколений, а также сохранение и развитие семейных и родословных традиций у граждан России ${ }^{3}$.

Практически во всех субъектах РФ проходят конкурсы поддержки профессиональных династий, в т.ч. специальные конкурсы поддержки медицинских династий. Не стала исключением и Ростовская обл. В 2017 г. губернатор Ростовской области Василий Голубев учредил новое почетное звание - «Трудовая династия Дона». Такое решение глава региона принял в целях возрождения, сохранения и развития преемственности семейных трудовых традиций в Ростовской обл. В целях повышения престижа врачебных профессий в Ростовской обл. ежегодно проводится конкурс «Лучший врач года» и учреждены премии в трех номинациях: «Лучший сельский врач», «Лучший молодой специалист», «Лучший организатор здравоохранения» 4 .

1 Династии земли российской. Доступ: https://www.oprf.ru/press/conference/2057 (проверено 11.07.2020).

2 Конкурс «Трудовые медицинские династии». Доступ: http://www.przrf.ru/news/full/ novosti-i-sobytiya/Konkurs-Trudovye-meditcinskie-dinastii/ (проверено 11.07.2020).

3 Моя родословная: навстречу 75-летию Великой Победы. Доступ: https://nra-russia. $\mathrm{ru} /$ sobyitiya-nra/2020/mart/moya-rodoslovnaya-navstrechu-75-letiyu-velikoj-pobedyi.html (проверено 11.07.2020).

4 Постановление Правительства Ростовской области от 18.11.2011 № 141 «О премиях Губернатора Ростовской области врачам областных государственных и муниципальных учреждений здравоохранения». Доступ: http://www.donland.ru/documents/O-premiyakhGubernatora-Rostovskojj-oblasti-vracham-oblastnykh-gosudarstvennykh-i-municipalnykhuchrezhdenijj-zdravookhraneniya?pageid $=128483 \& \mathrm{mid}=134977 \&$ itemId=22282 25.03.2020). 
Создание благоприятных условий для профессионального развития специалистов сферы здравоохранения, героизация образа врача в средствах массовой информации, активная государственная политика социально-экономической поддержки врачей в регионах будут способствовать формированию позитивного имиджа медицинской профессии и станут эффективным инструментом институциональной поддержки профессиональных династий врачей на всех уровнях.

Статья подготовлена при поддержке РНФ, проект № 19-18-00320.

\section{Список литературы}

Вольчик В.В., Посухова О.Ю. 2019. Институт профессиональных династий в контексте кланового капитализма. - Журнал институциональных исследований. T. 11. № 4. C. 77-89.

Иванова Е., Юрьев П. 2018. Профессиональные династии: тенденции и формы поддержки. - ХХІ Уральские социологические чтения. Социальное пространство и время региона: проблемы устойчивого развития: материалы международной научно-практической конференции. Екатеринбург: Гуманитарный университет. С. 498-503.

Инженерные династии России: монография (науч. ред. В.А. Мансуров). 2017. M.: POC. $331 \mathrm{c}$.

Калашникова К.А. 2012. Феномен династийности в процессе социальных изменений института здравоохранения. - Философия социальных коммуникаций. № 1(18). C. 149-156.

Колесникова Е.М. 2016. Инженерные династии: ресурс социальной мобильности и формирования группы. - Вестник Нижегородского университета им. Н.И. Лобачевского. Сер. Социальные науки. № 2. С. 104-110.

Левочкина А.В. 2015. Традиции семьи и карьерная направленность в образовании профессиональных династий. - Аналитика культурологии. № 3(33). C. 47-51.

Максимова Н.П. 2014. Династия - основа профессиональной карьеры. Образование. Карьера. Общество. № 3(42). С. 69-71.

Мостовая И.В., Посухова О.Ю., Клименко Л.В. 2019. Методологические аспекты исследования профессиональных династий в российском обществе. Гуманитарий Юга России. Т. 8. № 6. С. 70-82.

Нор-Аревян О.А. 2019. Факторы и преимущества формирования профессиональных династий врачей в советский период. - Государственное и муниципальное управление. Ученые записки. № 4. С. 240-245.

Посухова О.Ю. 2013. Профессиональная династия как результат семейных стратегий: инерция или преемственность? - Власть. № 2. С. 100-104. 
NOR-AREVYAN Oksana Avedikovna, Cand.Sci. (Soc.), Associate Professor of the Institute of Sociology and Regional Studies, South Federal University (105 Bolshaya Sadovaya St, Rostov-on-Don, Russia, 344006; noroks@yandex.ru)

\title{
INSTITUTIONAL CONDITIONS FOR SUPPORTING MEDICAL DYNASTIES IN MODERN RUSSIAN SOCIETY
}

\begin{abstract}
This article is devoted to the analysis of institutional environment for supporting professional dynasties of doctors in modern Russian society. Conditions both promoting and impeding professional reproduction in families and workplaces are considered. The author analyzes advantages and disadvantages of interfamily and intergenerational reproduction of the medical profession to determine any possible development prospects of its heredity. The article establishes that professional continuity through the dynasty inclusion constitutes a distinctive social practice in the healthcare sector. Moreover, the state undertakes the responsibility for supporting professional dynasty of doctors, and shifts it gradually from the range of family and corporate task to make it the goal of institutional support of the state. The author highlights elements of institutional support, such as health infrastructure development, targeted personnel policies, measures to increase the symbolic status of the dynasty, and propaganda of the advantages of dynasty in the media. The identified institutional barriers are proposed to be addressed at the federal and regional levels through the development of a comprehensive system of institutional support for professional dynasties of doctors.
\end{abstract}

Keywords: professional continuity, professional dynasty, doctor, institutional support, institutional support barriers, institutional tools 